\title{
PUBLIC RELATIONS CAMPAIGN IN DISSEMINATING HALAL FOOD AND BEVERAGES TO ELEMENTARY SCHOOL STUDENTS AND THE COMMUNITY
}

\author{
Andri Imam Subekhi ${ }^{1}$, Swastika Oktavia ${ }^{2}$ \\ Pendidikan Guru Sekolah Dasar, STKIP Babunnajah Pandeglang ${ }^{1}$ \\ Biologi, Universitas Mathla'ul Anwar Banten ${ }^{2}$ \\ Correspondence Author: andriimamsubekhi@gmail.com
}

\begin{abstract}
This study aims to analyze the public relations campaign in disseminating halal food and beverages to elementary school students and the community carried out by LPPOM MUI Banten. This study discusses issues related to campaign planning, implementation and evaluation. This research is a qualitative research using case study method and constructivism paradigm. Collecting data in this study through observation, interviews and documentation techniques. The results of this study indicate that the public relations campaign in disseminating halal food and beverages to elementary school students and the public by LPPOM MUI Banten is in accordance with the concept of the practical dimensions of the campaign. The planning stage uses analyzing problems, determining goals, determining goals, determining messages, determining time and determining costs. The implementation stage is by selecting the implementer, adjusting the delivery of the message and determining the media used. The evaluation process by looking at the reach of the target and changes in the attitude of the target.
\end{abstract}

Keywords : Public Relations Campaign; Socialization; Halal

Abstrak: Penelitian ini bertujuan untuk menganilisis kampanye public relations dalam mensosialisasikan makanan dan minuman halal kepada siswa sekolah dasar dan masyarakat yang dilakukan oleh LPPOM MUI Banten. Penelitian ini membahas masalah yang berhubungan dengan perencanaan, pelaksanaan dan evaluasi kampanye. Penelitian ini merupakan penelitian kualitatif dengan menggunakan metode studi kasus dan paradigma konstruktivime. Pengumpulan data dalam penelitian ini melalui teknik observasi, wawancara dan dokumentasi. Hasil dari penelitian ini menunjukkan bahwa kampanye public relations dalam mensosialisasikan makanan dan minuman halal kepada siswa sekolah dasar dan masyarakat oleh LPPOM MUI Banten sesuai dengan konsep dimensi praktis kampanye. Tahap perencanaan dengan menggunakan menganalisis masalah, menentukan tujuan, menentukan sasaran, menentukan pesan, menentukan waktu dan menentukan biaya. Tahap pelaksanaan dengan memilih pelaksana, menyesuaikan penyampaian pesan dan menetapkan media yang digunakan. Proses evaluasi dengan melihat dari terjangkaunya sasaran dan perubahan sikap sasaran.

Kata Kunci : Kampanye Public Relations; Sosialisasi; Halal 


\section{PENDAHULUAN}

Sumber daya manusia yang sehat, mampu berpikir kritis, kreatif dan inovatif merupakan tuntutan global yang harus dijawab oleh institusi Pendidikan bahkan sejak Pendidikan anak sekolah dasar maupun anak usia dini. Pengenalan tentang cara hidup sehat dan langkahlangkah pembiasaan telah menjadi bagian kegiatan sehari-hari di sekolah dasar. Pengenalan cara hidup sehat seperti mencuci tangan, kebiasaan mandi, serta makan yang teratur menjadi muatan pembelajaran yang bahkan dilatihkan pada anak saat berada di sekolah. Upaya ini dilakukan untuk menyiapkan suatu generasi yang sehat jasmani dan rohani, yang diyakini bakal menjadi manusia unggul kelak. (Wardhani, 2019) makanan dan minuman merupakan kebutuhan hidup yang mendasar bagi manusia. Untuk memenuhi kebutuhan tersebut maka perlu penyediaan bahan makanan dan minuman yang cukup baik dari aspek jumlah atau kuantitas maupun kualitasnya.

Tak dapat dipungkiri bahwa gaya atau pola makan dan minum anak tidak terlepas dari peran orang tua. Pada beberapa hal tertentu anak sekolah dasar tidak memiliki kemandirian untuk membuat keputusan dan seringkali hanya mengikuti kehendak orang tua. Sebaliknya dalam beberapa kasus, kemauan anak mendapat persetujuan dari orang tua.(Wardhani, 2019). Makanan dan minuman yang berkualitas sangat dibutuhkan oleh setiap orang, makanan dan minuman berkualitas adalah makanan dan minuman yang aman dan bergizi menjadi sangat krusial terutama sekali bagi anak sekolah dasar sebagai penerus bangsa.

Namun sejauh ini proses pembelajaran lebih menitikberatkan pengenalan produk makanan dan minuman serta alasan untuk mengkonsumsi agar sehat pada proses tumbuh kembagnya. Penekanan pembelajaran lebih banyak memberi pengetahuan praktis pada anak melalui konsep mengkonsumsi 4 sehat 5 sempurna dan bagi siswa yang muslim dikenalkan makanan dan minuman yang halal dikonsumsi. (Wardhani, 2019) produk makanan dan minuman yang bebas dari cemaran kimia, cemaran fisik dan mikrobiologis dalam Bahasa masyarakat sehari-hari dikenal dengan istilah bakteri atau kuman.

Kondisi yang dihadapi masyarakat saat ini terkait dengan adanya gelombang globalisasi, sehingga menempatkan nilai pengetahuan dan teknologi diposisi tertinggi sebagai prioritas utama dalam Pendidikan. (Munir, 2015) oleh karena itu anak-anak sekolah dasar harus lebih diperhatikan dalam kehidupan sehari-harinya terhadap kemajuan teknologi saat ini. Berkesinambungan dengan pembelajaran sekolah saat ini, banyak mengadopsi dari pembelajaran negara luar yang dianggap lebih maju. (Subekhi, 2021). Pada sisi lain terdapat degradasi secara mentalitas dan moralitas yang harus segera diselesaikan. Kondisi tersebut sehingga menuntut Pendidikan bukan hanya menyiapkan intelektual tinggi tetapi juga intelektual yang memiliki karakter agamis islami.

Konsep 4 sehat 5 sempurna merupakan konsep mengenalkan pada anak tentang makanan yang memiliki gizi seimbang, yang terdiri atas nasi atau bahan pengganti lain, lauk, sayur, buah dan dilengkapi dengan susu. Sedangkan untuk konsep halal yang dikenalkan adalah makanan dari bahan daging babi, minuman yang memabukkan (mengandung alkohol) 
dan makanan bersumber dari hewan yang disembelih tidak dengan mengucap nama Allah. Kajian akan pentingnya mengenalkan pada anak tentang produk makanan atau jenis makanan yang sehat melalui proses belajar dikemukakan oleh, (Allirot, Maiz dan Urdaneta, 2017).

Banyak orang tua yang memberikan makanan atau menuruti keinginan anak untuk mengkonsumsi makanan yang sebenarnya sudah diperkaya dengan perasa, penyedap, atau pewarna tanpa menyadari bahwa makanan tersebut membuat anak tidak mengenali rasa asli suatu makanan. (Henninger, 2013) anak seharusnya memahami tentang pentingnya hidupu sehat.

Jajanan yang banyak tersedia dan yang mudah diakses saat ini oleh anak-anak sekolahan termasuk anak-anak siswa sekolah dasar adalah jajanan yang tidak jarang kurang memenuhi persyaratan pangan yang berkualitas, bahkan kadang bisa termasuk dalam kategori makanan dan minuman yang kurang aman untuk dikonsumsi, (Zaini, 2019) sedangkan pemahaman anak-anak tentang makanan yang aman, bergizi dan halal sangat rendah.

Hal ini selaras dengan pendapat (Mayesky, 2012) bahwa mengenalkan anak tentang konsep pangan yang baik haruslah dengan memberi anak kesempatan berkegiatan dengan bahan pangan yang sesungguhnya dan memberi sebanyak mungkin kesempatan pada anak untuk memilih, menyiapkan, dan menikmati hidangan yang merangsang munculnya pengalaman baru tentang makanan yang dikonsumsi.

Banyaknya produk-produk non-halal dan subhat yang beredar ditengah masyarakat tanpa dipungkiri disebabkan oleh perkembangan teknologi, termasuk di dalam teknologi pembuatan pangan. Sebagai contoh, dahulu orang membuat roti cukup hanya menggunakan bahan dasar tepung terigu, ragi dan air. Akan tetapi, sekarang tidak cukup hanya dengan bahan utama seperti tepung dan gula saja, tetapi perlu ada tambahan lainnya yang disebut dengan bahan tambahan makanan seperti mentega putih, perisa atau bahan menimbulkan aroma dan rasa tertentu.

Bagi orang awam, bahan-bahan tersebut tentu tidak menimbulkan pertanyaan aka nasal tidak dianggap berbahaya dan sah saja untuk dikonsumsi, namun berdasarkan penelitian para ahli diketahui bahwa bahan-bahan tambahan tersebut (contoh: shortening) ada yang mengandung lemak babi atau bahan yang dapat berasal dari lemak babi yang diperoleh melalui reaksi kimia dengan menggunakan bahan awal yang berasal dari babi. Sehingga butuh usaha yang cukup ekstra untuk mengetahui mana yang halal dan mana yang tidak hal.

Selanjutnya terdapat juga aspek penting lainnya terkait makanan yaitu ketentuan tentang kehalalan makanan. Aspek ini sangat penting untuk dicakup dalam pembelajaran khususnya bagi anak-anak siswa SD yang muslim. Sesuai dengan yang dipersyaratkan dalam agama islam bahwa dalam menyediakan dan mengkonsumsi makanan harus memperhatikan dua aspek dasar yaitu halalan dan toyyiban. Makanan yang halal adalah produk makanan yang terbuat dari bahan yang halal dan melalui tahapan proses pengolahan yang halal. Produk makanan yang beredar bagi masyarakat muslim di Indonesia diharuskan untuk mempunyai 
jaminan kehalalannya. Jaminan kehalalan tersebut ditunjukkan dengan adanya nomor sertifikat halal pada masing-masing kemasan produk makanan.

Seorang muslim sudah seharusnya selalu mengkonsumsi segala sesuatu yang baik yang telah disediakan Allah di bumi ini untuk menjaga kualitas jasmani dan rohani kita agar tidak rusak oleh asupan sesuatu yang haram. Memperhatikan apa yang kita konsumsi, teliti akan tabel komposisi sebuah produk menjadi penting. Namun seberapa besar perhatian seorang konsumen muslim terhadap hal ini dapat menjadi berbeda-beda.

\section{METODE}

Penelitian ini merupakan penelitian kualitatif dengan menggunakan model studi kasus dan paradigma konstruktivime. Pengumpulan data dalam penelitian ini yaitu melalui teknik observasi, wawancara dan studi dokumentasi.

\section{HASIL DAN PEMBAHASAN}

Teori yang dijadikan landasan dalam peneliti ini adalah kampanye, public relations, kampanye public relations, sosialisasi, halal, masyarakat dan konsep dimensi praktis kampanye. Kampanye pada prinsipnya adalah contoh tindakan persuasi secara nyata (Venus, 2009: 7). Kampanye sebagai sebuah kegiatan komunikasi yang serangkaian tujuan yang telah terorganisasi dan bertujuan untuk menciptakan dampak tertentu kepada sasaran yang dtuju dengan waktu tertentu serta berkelanjutan (Ruslan, 2005: 23).

Menurut Griswold (1948) mengungkap tentang batasan PR yaitu Public Relations is the management functions which evaluates public attitudes, identifies the policies and procedures of an individual organization with the public interest and plans excutes a program action to learn public understanding and acceptance (PR adalah fungsi manajemen yang mengevaluasi publik, memperkenalkan berbagai kebijakan dan prosedur dari suatu individu atau organisasi berdasarkan kepentingan publik, dan membuat perencanaan, dan melaksanakan suatu program kerja dalam upaya memperoleh pengertian dan pengakuan publik) (Soemirat \& Ardianto, 2012: 12).

Public Relations menurut Jefkins adalah Public Relations consist of all forms of planned communication, outwards and inwards, between an organization and its publics for the purposes of achieving specific objectives concerning mutual understanding (Public) Relations merupakan keseluruhan bentuk komunikasi yang terencana, baik itu keluar maupun ke dalam, yakni antara suatu organisasi dengan publiknya dalam rangka mencapai tujuan yang spesifik atas dasar adanya saling pengertian) (Yulianita, 2001: 33). Sebuah kegiatan yang dilakukan untuk meningkatkan kesadaran dan pengetahuan masyarakat serta menarik perhatian dan persepsi atau opini yang positif dari masyarakat terhadap suatu kegiatan yang diadakan oleh suatu lembaga atau organisasi yang mengharapkan adanya rasa simpati dan kepercayaan masyarakat terhadap lembaga atau organisasi tersebut, dan dilakukan dengan menggunakan komunikasi melalui penyampaian pesan yang baik, intensif dan berkelanjutan. 
Kampanye Public Relations juga digunakan sebagai pemberian penerangan dan pengertian terus-menerus serta memberikan motivasi kepada masyarakat dalam suatu kegiatan agar menciptakan citra yang positif. (Ruslan, 2005: 66). Soejono Dirdjosisworo (1985) menyatakan bahwa sosialisasi mengandung tiga pengertian, yaitu 1) Proses sosialisasi adalah proses belajar, yaitu suatu proses akomodasi dengan nama individu menahan, mengubah impuls-impuls dalam dirinya dan mengambil alih cara hidup atau kedubayaan masyarakatnya. 2) Dalam proses sosialisasi itu individu mempelajari kebiasaan, sikap, ide-ide, pola-pola nilai dan tingkah laku, dan ukuran kepatuhan tingkah laku di dalam masyarakat di mana ia hidup. 3) Semua sifat dan kecakapan yang dipelajari dalam proses sosialisasi itu disusun dan kembangkan sebagai suatu kesatuan sistem dalam diri pribadinya (Abdulsyani, 2012: 57). Makanan adalah sebuah bahan, yang biasanya berasal dari hewan atau tumbuhan, yang dimakan oleh makhluk hidup mendapatkan tenaga dan nutrisi (Amaliyah, 2017: 5).

Halal adalah segala sesuatu yang boleh dikonsumsi (seperti makanan dan minuman) ataupun dimiliki dan dipergunakan (seperti benda-benda yang bisa dipakai), baik itu halal dari zat-zat yang terkandung dalam makanan, halal secara memprosesnya (seperti cara menyembelihnya, cara memasak), kemudian halal cara memperolehnya (Ayodya dan Koswara, 2014).Makanan halal adalah makanan yang boleh dimakan oleh umat Islam. Orang beriman akan taat dan hanya memakan makanan halal. Mengonsumsi makanan halal, hidup akan menjadi lebih baik dan bertakwa"(Wahyudin dkk, 2008: 18). Perkataan masyarakat berasal dari kata musyarak (arab), yang artinya bersama-sama, kemudian berubah menjadi masyarakat, yang artinya berkumpul bersama, hidup bersama dengan saling berhubungan dan saling mempengaruhi, selanjutnya mendapatkan kesepakatan menjadi masyarakat (Indonesia) (Abdul Syani, 2012: 30).

Konsep dimensi praktis kampanye adalah konsep yang dipaparkan oleh Antar Venus. Dalam bukunya beliau memaparkan bahwa ada lima tahapan dalam dimensi praktis kampanye yaitu perencanaan kampanye, riset formatif untuk desain kampanye, mempersiapkan anggaran kampanye, pelaksanaan kampanye, dan evaluasi kampanye. Namun, yang peneliti ambil hanya tiga tahapan yaitu perencanaan kampanye, pelaksanaan kampanye dan evaluasi kampanye. Sedangkan untuk anggaran kampanye peneliti memasukannya ke dalam perencanaan kampanye.

Pertama, perencanaan merupakan tahap yang harus dilakukan agar kampanye dapat mencapai tujuan yang diinginkan (Venus, 2009: 143). Kedua, pelaksanaan kampanye adalah penerapan dari konstruksi rancangan program yang telah ditetapkan sebelumnya. Karena sifatnya yang demikian maka prose pelaksanaan harus secara konsisten berpedoman kepada rancangan yang ada tanpa mengabaikan penyesuaian yang perlu dilakukan sesuai dangan kenyataan lapangan yang dihadapi (Venus, 2009: 199). Ketiga, evaluasi kampanye diartikan sebagai upaya sistematis untuk menilai berbagai aspek yang berkaitan dengan proses pelaksanaan dan pencapaian tujuan kampanye (Venus, 2009: 210). 


\section{KESIMPULAN}

Berdasarkan hasil temuan dan pembahasan mengenai kampanye public relations dalam mensosialisasikan makanan dan minuman halal kepada siswa sekolah dasar dan masyarakat yang dilaksanakan oleh LPPOM MUI Banten terdapat tiga tahapan yang digunakan. Tiga tahapan tersebut terdiri dari perencanaan, pelaksanaan dan evaluasi. Setiap Kampanye Public Relations dalam Mensosialisasikan Makanan dan Minuman Halal kepada siswa sekolah dasar dan Masyarakat Tabligh: Jurnal Komunikasi dan Penyiaran Islam Vol. 3 No. 3 (2018) 60-79 77 tahapan mempunyai beberapa kegiatan yaitu 1) Tahap perencanaan mempunyai beberapa tahap yaitu menganilis masalah, menentukan tujuan, menentukan sasaran, menentukan pesan, menentukan waktu, dan menentukan anggaran biaya; 2) Tahap pelaksanaan terdiri dari pelaksana kegiatan, penyesuaian penyampaian kepada sasaran dan media yang digunakan; 3) Tahap evaluasi terdiri dari terjangkaunya sasaran, pesan yang diterima, perubahan sikap sasaran.

Kegiatan kampanye ini adalah sebuah kegiatan yang sangat positif untuk menambah pengetahuan dan kesadaran masyarakat mengenai pentingnya mengkonsumsi makanan dan minuman halal. Selama ini pula kegiatan ini sudah berjalan dengan sangat baik, namun di dalam segala sesuatu pastinya selalu ada yang tidak sempurna dan nantinya akan membuat kegiatan ini semakin baik lagi. 1) Kurangnya anggota karyawan terkadang membuat suatu lembaga kesulitan dalam mengatur beberapa kegiatan sehingga dibutuhkan anggota karyawan yang mampu melengkapi kekurangan tersebut khususnya di bagian public relations, karena lembaga sebesar ini akan sangat membutuhkan peran seorang public relations. 2) Semakin ditambah lagi kegiatan sosialisasi khususnya mungkin di daerah pelosok seperti tempat tinggal peneliti, karena peneliti menyadari terkadang masyarakat daerah yang mungkin sebagian masyarakatnya belum terbuka dengan dunia luar masih kesulitan dalam menyikapi produk halal.

\section{DAFTAR PUSTAKA}

Abdulsyani. (2012). Sosiologi Skematika, Teori, dan Terapan. Jakarta : PT. Bumi Aksara.

Amaliyah, N. (2017). Penyehatan Makanan dan Minuman. Yogyakarta : Deepublish.

Amalia, N F. (2012). Kampanye Public Relations Dalam Membentuk Sikap Khalayak (Studi pada Kampanye Stop the Trafficking of Children and Young People yang Diselenggarakan Oleh The Body Shop Indonesia). Skripsi. Jurusan Hubungan Masyarakat, Universitas Indonesia, Depok.

Amalya, R. (2015). Strategi Kampanye Public Relations Listrik Pintar PT. PLN (Persero) Wilayah Riau dan Kepulauan Riau dalam Mewujudkan Smart Consumer di 
Pekanbaru. Jom FISIP Vol.2 No.2 Oktober 2015. Skripsi. Jurusan Ilmu Komunikasi, Universitas Riau, Riau.

Ayodya, W. Endang K. (2014). 110 Solusi Jadi Pengusaha yang Berkah. Jakarta : PT. Elex Media Komputindo.

Allrot. X., Maiz. E., Urdaneta. E., 2017. Shopping for food with children: A strategy for directing their choices toward novel foods containing vegetables. Appetite. Vol 120. P 287 -296. DOI: https://doi.org/10.1016/j.appet.2 017.09.008.

Henniger, M.L. 2013. Teaching Young Children: an Introduction, Boston: Pearson.

Munir, Misbahul,. (2015), Nilai-Nilai Islam Dalam Bahan Ajar Tematik Makananku Sehat dan Bergizi: Suatu Konsep Integratif Pembelajaran di Madrasah Ibtidaiyah., Madrasah, Vol. 7 No. 2, pp. 289-308.

Mayesky, M. 2012 Creative Activities For Young Children. 10th edition. United States: Cengage.

Ruslan, R. (2005). Kiat dan Strategi Kampanye Public Relations. Jakarta : PT. Raja Grafindo Persada.

Soemirat, S. Elvinaro A. (2012). Dasar-Dasar Public Relations. Bandung: PT. Remaja Rosdakarya.

Subekhi, A., I., (2021), Studi Etnomatematika: Kain Berbahan Dasar Halal Ditinjau dari Motif Sadulur Batik Lebak Provinsi Banten, IJMA: International Journal Mathla'ul Anwar of Halal Issues, Vol 1 No. 1, pp. 27-39.

Venus, A. (2009). Manajemen Kampanye Panduan Teoretis dan Praktis dalam Mengefektifkan Kampanye Komunikasi. Bandung : Simbiosa Rekatama Media.

Wardani, RWK. (2017). Strategi Komunikasi Badan Amil Zakat Nasional dalam Pengumpulan Zakat Maal dalam Ilmu Dakwah: Academic Journal For Homiletic Studies, 1 (11) 151-176.

Wardhani,Wahju Dyah Laksmi, Tri Endang Jatmikowati, Angraeny Unedia Rahman., (2019), Pangan Thoyyibah: Mengenalkan Gaya Hidup Sehat Pada Anak Usia Dini, Early Childhood: Jurnal Pendidikan, Vol. 3 No. 2, pp. 1-14.

Yulianita, N. (2001). Dasar-Dasar Public Relations. Bandung: Multimedia, Fikom Unisba.

Zaini, M Abbas, Zainuri, Yeni Sulastri, Rucitra Widyasari, \& Rini Nofrida., 2019, Pembelajaran Interaktif Tentang Pangan Aman, Bergizi dan Halal Bagi Siswa Sekolah Dasar, Jurnal Abdi Mas TPB, Vol 1 No 1, pp. 70-78 